\title{
MEMÓRIA CULTURAL EM UN EPISODIO EN LA VIDA DEL PINTOR VIAJERO DE CÉSAR AIRA
}

\author{
Günther Augustin*
}

\begin{abstract}
Resumo: Analisamos ${ }^{1}$ a novela Un episodio en la vida del pintor viajero, de César Aira, sob o ponto de vista da representação da memória cultural latino-americana. Argumentamos que a viagem narrada no texto é uma alegoria da busca de um procedimento artístico que seria melhor do que o discurso teórico-científico, na verdade. Mostramos como o texto sugere que cada discurso se enquadra numa ordem e o procedimento artístico se enquadra na ordem da representação. Essa ordem foi determinada pela visão europeia na qual se destacaram dois ícones da memória latino-americana, Alexander von Humboldt e Johann Moritz Rugendas, o protagonista da novela. Sob o ponto de vista da nossa análise, e também do nosso argumento, focalizamos aspectos que a crítica e os comentaristas têm ignorados: o de que a questão da representação da memória histórica estaria relacionada ao encontro violento do homem branco com o índio em um combate de civilizações. Aplicamos neste artigo, nosso modelo de análise da interdiscursividade de textos culturais.
\end{abstract}

Palavras-chave: Memória cultural; discurso; representação; Alexander von Humboldt; Johann Moritz Rugendas.

\section{Introdução}

Para o leitor desavisado, a novela Un episodio en la vida del pintor viajero de César Aira conta a história de um pintor viajante pelos pampas argentinos de forma cativante, tanto pelo

* Universidade Federal de Minas Gerais.

${ }^{1}$ Agradeço à CAPES pela bolsa de pós-doutorado que possibilitou este trabalho. 
estilo quanto pela narrativa que gira em torno de um episódio dramático que forma o núcleo do texto. O leitor comentarista literário logo percebe alguns desvios da forma tradicional e convencional da novela. $\mathrm{O}$ autor dividiu o episódio central em duas partes e uma parte final. Alguns trechos discursivos giram em torno da complexa questão do procedimento artístico em suas dimensões epistemológicas e históricas gerando um texto hibrido em vários aspectos. Para o leitor com memória cultural fica evidente que a novela é um documento que trata da memória cultural como uma função da ordem da representação. Para mostrar isso, faremos uma análise sob o ponto de vista da memória cultural latino-americana presente no texto e como ela é ligada à questão da representação.

A novela é um texto híbrido, denso e complexo. É ao mesmo tempo fato e ficção, relato de viagem e narrativa de um acontecimento extraordinário, misturando descrição intuitiva e reflexão discursiva. Antes do próprio relato da viagem do pintor viajante com seu amigo, o narrador oferece uma pequena retrospectiva sobre a história dos Rugendas desde o século XVII, quando a família migrou da Catalunha para Augsburg na Alemanha por motivos religiosos. O narrador destaca o início da dinastia dos Rugendas como pintores e as mudanças de gênero dos seus quadros. Foram pintores de quadros de batalhas até a época de Napoleão. Em função da "época de paz" na Europa após as guerras napoleônicas, Johann Moritz Rugendas mudou para as classes de pintura da natureza. Sua primeira viagem famosa, e que originou sua fama, foi no Brasil:

Rugendas por su parte, al cabo de cuatro años de excursiones y trabajos por las provincias de Rio de Janeiro, Minas Gerais. Mato Grosso, Espíritu Santo y Bahía, regresó a Europa y publicó un bello librito ilustrado, el Viaje Pintoresco por el Brasil (el texto fue redactado por Víctor Aimé Huber en base a las notas del pintor), que hizo su fama y lo puso en contacto 
con el eminente naturalista Alexander von Humboldt, con quien colaboró en algunas publicaciones. (p. 10) ${ }^{2}$

A novela conta a primeira viagem de Johann Moritz Rugendas na Argentina, em 1837, cuja finalidade teria sido desmentir seu amigo e admirador Alexander von Humboldt. Depois da retrospectiva biográfica dos Rugendas, inicia-se a descrição da viagem com a travessia dos Andes e os pampas em direção a Buenos Aires. No centro do pampa, em um lugar quase deserto. Rugendas sofre um acidente de dimensões cósmicas quando é atingido por uma tempestade elétrica, ficando ele e seu cavalo literalmente eletrificados pelos raios. Arrastado pelo chão árido, o rosto do pintor fica mutilado com alguns nervos expostos. Hospedado em São Luiz, recupera-se, mas fica com um rosto deformado, monstruoso, e ele depende de doses de morfina para aplacar a dor. Volta para Mendoza, onde em uma fazenda consegue o que sempre esperou: a experiência de um malón, ou seja, de um ataque de índios. A novela termina com a parte final do episódio, na qual Rugendas procura os índios retirados no mato para desenhar seus rostos. O texto conclui com a data da escrita (24 de novembro de 1995), tendo sido publicado em 2000.

É na última parte do texto, com o encontro de um artista branco europeu com os índios, que identificamos a questão da representação e sua relação com a questão da memória cultural como um motivo central da novela, um leitmotiv que ficou quase despercebido pelos comentaristas e críticos. Não pode ser por acaso que o termo-chave "ordem da representação" aparece na descrição do momento mais intenso do encontro: Rugendas cuerpo a cuerpo com os selvagens, e eles cuerpo a cuerpo com o branco. Também não deve ser por acaso que o termo lembra, por analogia, o conceito de "ordem do discurso". Na nossa análise

${ }^{2}$ Ao longo deste artigo, números entre parênteses referem-se a páginas em AIRA. Un episodio en la vida del pintor viajero. 
levaremos em conta a ordem do discurso da época do episódio narrado bem como a do narrador contemporâneo. Aplicaremos nosso método de leitura da interdiscursividade de textos culturais. ${ }^{3}$ Quando analisamos o texto do ponto de vista da sua discursividade, utilizamos os termos discurso, discursivo e ordem do discurso em três dimensões:

1. Entendemos discurso também como fala ou escrita a partir de um determinado ponto de vista, seja ele explicito ou implícito, cujo sentido é derivado do perspectivismo de Nietzsche. ${ }^{4}$ Nesse sentido consideramos todo texto um discurso, e muitas vezes o discurso provoca seu próprio contra-discurso. No texto literário, esse aspecto se aplica, ainda à estrutura narrativa também, e com isso a sua multiplicidade de discurso, o que chamamos interdiscursividade.

2. Entendemos discursivo como o contrário de intuitivo, uma distinção que encontramos em Kant. Discursivo seria a fala ou escrita teórica, abstrata e conceitual, enquanto a intuitiva seria concreta, imaginativa, poética, sendo esta, portanto a forma da literatura.

3. Na fórmula ordem do discurso, entendemos discurso como utilizado por Foucault no sentido de regras, de novo explicito ou implícito, o que pode ser dito ou não, sendo estas regras determinadas por estruturas de poder.

Identificamos e comentamos os discursos em trechos significativos que darão sustentação ao nosso argumento de que o narrador da novela narra a viagem do pintor viajante como alegoria da busca da verdade pela representação artístico, procurando estabelecer uma relação entre o conhecimento da história e da memória cultural através desta representação, e de que a ordem da representação é determinada pela ordem do discurso.

\footnotetext{
${ }^{3}$ AUGUSTIN. Kultur als Text, Text als Diskurs - Interdiskursive Analyse interkultureller Texte, p. 27.

${ }^{4}$ AUGUSTIN. Literatura de viagem na época de Dom João VI, p. 12.
} 


\section{Os discursos}

Lendo a primeira frase do livro, temos indícios de um narrador hibrido que fala ora com voz própria ora pela voz do protagonista pintor viajante: "En Occidente hubo pocos pintores viajeros realmente buenos. El mejor de los que tenemos noticias y abundante documentación fue el gran Rugendas..." (p. 7) . A novela é contada na primeira pessoa plural, em uma perspectiva muito menos subjetiva do que a da primeira pessoa, porém menos objetiva do que a da terceira pessoa. E essa forma vai se confirmando ao longo do texto, principalmente quando o narrador ou fala de Rugendas ou fala através da voz dele. O caráter documentativo tanto da narrativa quanto da pintura do protagonista é enfatizado com frequência. O narrador alega contar a história como ela foi contada nas cartas que Rugendas escreveu para sua irmã. Nesse sentido podemos considerar a novela um documento ficcional da memória cultural. Na longa segunda frase, lemos como a narrativa se situa no tempo e no espaço. O texto refere-se à segunda viagem de Rugendas à Argentina, em 1847, e na frase seguinte à primeira, dez anos antes, quando o episódio que consta no título da novela teria acontecido. Ainda na segunda frase temos as referências locais "Argentina... los paisajes y tipos rioplatenses" sendo este lugar especifico caraterizado de forma irônica como "este rincón del mundo" (p. 7). A ironia do narrador indica sua consciência da situação histórica global expressa no uso dos termos "Occidente" logo no início da primeira frase e o "Nuevo Mundo" no final da segunda, dando essas referências como parâmetros geográficos do discurso sobre a América Latina, que no passado era sempre ditado pelas vozes do velho mundo europeu. ${ }^{5}$ Uma dessas vozes mais influentes foi a de Alexander von Humboldt. O nome dele consta duas vezes na segunda frase, o que indica sua importância nessa novela, quando ficamos sabendo

\footnotetext{
${ }^{5}$ ETTE. Nachwort. In: AIRA. Humboldts Schatten, p. 112.
} 
que a viagem de Rugendas "sirvió para desmentir a su amigo y admirador Humboldt, o más bien a una interpretación simplista de la teoría de Humboldt ..." (p. 7). Humboldt não é o protagonista da novela, mas seu discurso serve como ponto de partida das reflexões do pintor protagonista sobre a questão da representação artística e seu enquadramento na ordem do discurso.

Os discursos que identificamos, ainda conforme nosso modelo de discursos culturais, são os do encontro intercontinental e intercultural, ao qual já referimos: os do naturalista e os do artista, representados por Humboldt e Rugendas, que procura articular um contra-discurso em relação à proposta de Humboldt; os discursos étnicos dos brancos e dos índios, mesmo que estes se manifestem menos por palavras e mais pelo silêncio e por gestos; e um discurso de gênero feminino na figura da mulher do fazendeiro que empresta uma mantilla a Rugendas e aproveita o momento para indicar o papel dela na luta das culturas que o malón representa nessa novela.

\section{O discurso de Humboldt e o contra-discurso de Rugendas}

No final da retrospectiva genealógica no início da novela e antes do relato da viagem, o narrador gasta três páginas para nos apresentar a proposta de procedimento de Alexander von Humboldt. $\mathrm{O}$ resumo mais sucinto está no parágrafo seguinte:

Rugendas fue un pintor de género. Su género fue la fisionómica de la Naturaleza, procedimiento inventado por Humboldt. Este gran naturalista fue el padre de una disciplina que en buena medida murió con él: la Erdtheorie, o Physique du Monde, una suerte de geografía artística, captación estética del mundo, ciencia del paisaje. Alexander von Humboldt (17691859) fue un sabio totalizador, quizás el último; lo que pretendía era aprehender el mundo en su totalidad; el camino que le pareció el adecuado para 
hacerlo fue el visual, con lo que adhería a una larga tradición. ... El geógrafo artista debía captar la «fisionomía» del paisaje... (p. 10-11)

Nesse resumo do procedimento da fisionomia da natureza de Humboldt o narrador capta a síntese de ciência e arte, a visão totalizadora e a manipulação da sensibilidade do observador inerente a esta visão. O único juízo expresso é que Humboldt "fue un sabio totalizador, quizás el último". Assim ele seria o último em uma longa tradição. Com essa avaliação, o narrador encontrase em concordância com muitos comentaristas de hoje, mas não com todos. Há inclusive uma redescoberta da abordagem humboldtiana e do "humboldtian writing". ${ }^{6}$ Pela primeira frase do parágrafo, Rugendas faria parte dessa tradição. Conforme o primeiro parágrafo da novela, porém, sabemos que a segunda viagem do pintor "sirvió para desmentir a su amigo y admirador Humboldt" (p. 7). O que quer dizer isso?

Do início, Rugendas é apresentado como um artista que busca a inovação: "Por esos años Rugendas había iniciado una práctica novedosa, la del boceto al óleo. Esto constituía una innovación, que la historia del arte ha registrado como tal. ... Y lo era, en buena medida, pero tenía como horizonte una transvaloración de la pintura." (p. 21). Em outro momento, a inovação se enquadra na arte de vanguarda: "En los detalles, a su vez, se recuperaba lo extraño, lo que cien años después se llamaría 'surrealista', y en aquel entonces era la 'fisionómica de la naturaleza', vale decir el procedimiento." (p. 76).

Há momentos no texto nos quais o questionamento do procedimento é articulado de forma mais enfática: "La ambición absolutista provenía de Humboldt, que había ideado el procedimiento como una máquina general del saber. Desarmando ese autómata pedante, quedaba la multiplicidad de los estilos, y éstos tomados

\footnotetext{
${ }^{6}$ ETTE, Überlebenswissen, p. 31.
} 
de a uno eran acción.” (p. 48). Desmentir um procedimento implica uma reflexão sobre a questão do procedimento em si. Querendo desmentir a teoria de Humboldt significa, portanto, questionar ou até desconstruir a construção da memória deixada por ele. É isso o que o pintor viajante Rugendas faz ao longo da novela, muitas vezes em conversas com seu amigo que o acompanha. É nesses trechos mais discursivos, isto é, onde o relato apresenta, em termos abstratos e conceituais, opiniões e reflexões de Rugendas, que a voz do narrador se mistura com a do pintor.

Uma caraterística da novela de Aira é sua alternância entre descrição intuitiva poética e reflexão discursiva. Nas reflexões, o narrador ou os próprios viajantes expressam seus pensamentos em torno da questão da representação, do procedimento artístico e às vezes em relação a questões epistemológicas relativas à pintura e, por analogia, à escrita. Lendo o texto do ponto de vista da memória cultural, procuramos identificar como as reflexões são inter-relacionadas, às vezes de forma bastante paradoxal, sugerindo uma relação entre a pintura, a escrita, a história, a geografia, o Outro e o índio. Como o protagonista pintor viajante se encontra na busca de um procedimento autêntico, o narrador parece encontrar-se no mesmo caminho. Começamos com a conversa de forma e conteúdo exemplar para nossa análise. É interessante notar o contexto estético em volta do trecho discursivo. O leitor é levado a esse trecho da seguinte maneira: "El viejo baqueano los entretenía con cuentos a la noche. El hombre era un tesoro de información de la historia regional." (p. 30). Fisicamente presente no local da história regional que estão ouvindo pela voz do guia local, que lembra o narrador autêntico benjaminiano, levantam o tema da história para em seguida voltar para um intenso momento de intuição que toca inclusive a fascinação obsessiva de Rugendas, a imensidade das planícies do pampa argentino: "Un pájaro se escurría por el cielo vacío. Detenida en el horizonte, como un lucero del mediodía, una carreta. ¿Cómo volver a hacer una llanura igual?” (p. 31). 
Enquadrado esteticamente, o narrador relata a seguinte conversa:

Por algún motivo, seguramente por no estar pintando, Rugendas y Krause encontraron en sus conversaciones diuturnas de caballo a caballo una relación entre pintura e historia. Un punto en el que se habían puesto de acuerdo era la ventaja de la historia para saber cómo se hacían las cosas. Una escena, natural o cultural, por detallada que fuera, no decía cómo se había llegado a ella, cuál era el orden de las apariciones ni el encadenamiento causal que había llevado a esa configuración. Y justamente, la abundancia de relatos en que se vivía quedaba explicada por la necesidad del hombre de saber cómo se habían hecho las cosas. Ahora bien, a partir de este punto, Rugendas iba un paso más allá, para sacar una conclusión paradójica. A título de hipótesis, proponía que el silencio de los relatos no implicaba pérdida alguna... En lugar del relato, y realizando con ventaja su función, lo que debía transmitirse era el conjunto de «herramientas» con el que poder reinventar, con la espontánea inocencia de la acción, lo que hubiera sucedido en el pasado. Lo más valioso que hicieron los hombres, lo que valía la pena que volviera a suceder. Y la clave de esa herramienta era el estilo. Según esta teoría, entonces, el arte era más útil que el discurso. (p. 30-31)

O trecho é exemplar para a forma como o narrador apresenta reflexões epistemológicas através da voz do protagonista. $\mathrm{Na}$ primeira parte, os dois amigos estão de acordo. Na segunda, Rugendas se apresenta como inovador. O trecho é exemplar também para o conteúdo da maioria das reflexões na medida em que são de difícil entendimento e muitas vezes chegam a uma conclusão paradoxal. À primeira vista, as reflexões do pintor viajante articulam a sua visão de que a arte é mais útil do que o 
discurso. Mas essa teoria é fruto de considerações mais gerais. A repetição das palavras no mesmo parágrafo: "cómo se hacían las cosas (...) cómo se habían hecho las cosas" indica a centralidade da questão da verdade na sua historicidade.

Encontramos aqui uma visão construtivista e desconstrutivista. As coisas são feitas. Na distinção entra cena natural e cultural, fenômenos culturais sempre são construídos ou configurados. Quando se fala em relatos, pensamos na multiplicidade dos discursos e como cada época reinventa a história. Rugendas parece sugerir que com as respectivas ferramentas poderíamos construir, desconstruir e reconstruir as visões da história e do mundo.

\section{Ordem do discurso}

Notamos um uso frequente da palavra "ordem" no sentido de ordem das coisas e ordem do discurso. No trecho citado acima, os dois conversam sobre "el orden de las apariciones (...) que había llevado a esa configuración.” (p. 30). Quando o narrador nos faz ler os pensamentos de Rugendas, este em determinado momento se preocupa com o fato de que o texto da sua famosa obra sobre o Brasil foi escrito por um outro que simplesmente teria dado ordem às fabulações do pintor:

Y la verdad, tal como ahora se le aparecía, era que todo formaba parte de lo mismo. Con lo que el escritor mercenario, el "négre", se metía en la esencia misma del trabajo, bajo la excusa de estar llenando una función puramente técnica, la redacción ordenada en frases de los balbuceos inconexos de la documentación hablada. iPero todo era documentación! iEse era el principio y el fin del juego! El principio sobre todo (porque el fin se perdía en los recorridos nebulosos de la historia del arte y la ciencia). La Naturaleza misma, afectada a priori por el procedimiento, ya era documentación. No había 
datos inconexos. El orden ya estaba implícito en la revelación fenoménica del mundo, el orden del discurso conformaba las cosas mismas. Y en ese orden participaba su actual estado, del que en consecuencia era necesario examinar el aparente caos visionario o maniático y reducirlo a sus formas de razón. (p. 55)

A segunda parte dessa reflexão articula uma visão construtivista que pode ser derivada da filosofia de Kant: aproximamonos dos fenômenos a partir de um procedimento pré-estabelecido e interpretamos o mundo conforme a ordem do discurso. ${ }^{7}$

Tratando-se de uma viagem como alegoría da busca; o motivo da busca para desmentir Humboldt é relacionado a espaços geográficos definidos que o pintor está buscando para encontrar seu procedimento: "el objetivo secreto de su largo viaje, que abarcó toda su juventud, fue la Argentina, el vacío misterioso que había en el punto equidistante de los horizontes sobre las llanuras inmensas. Sólo allí, pensaba, podría encontrar el reverso de su arte..." (p. 10-11). Ou em outras palavras: "A esta altura de su carrera, y con el gran vacío de las pampas al alcance de la mano, sentía que lo más auténtico de su arte iba en la dirección contraria" (p. 26). Ou: "Era una recta que terminaba en Buenos Aires, pero lo que le importaba a Rugendas estaba en la línea, no en el extremo. En el centro imposible. Donde apareciera al fin algo que desafiara a su lápiz, que lo obligara a crear un nuevo procedimiento." (p. 29). Fernández lembra que o aspecto da linha faz parte da poética de Aira: "la conversión de las acepciones de derecha e izquierda en una línea recta, inversiones y desplazamientos que consolidan en definitiva la noción de continuo". 8

\footnotetext{
${ }^{7}$ Não temos o espaço neste trabalho para mostrar como os a priori's kantianos do tempo e do espaço são articulados no estilo da novela.

${ }^{8}$ FERNÁNDEZ. Narraciones viajeras: César Aira y Juan José Saer, p. 19.
} 


\section{O índio no discurso do branco}

Além de ser relacionada a um lugar geográfico definido, a questão da representação e do procedimento relaciona-se ao encontro entre o homem branco e o índio, exemplificado na detalhada descrição de um malón. É notável como no texto da novela os conceitos procedimiento, procedimiento bumboldtiano, procedimiento del combate, episodio, episodio del largo combate, bistoria, malón, bistoria general del malón, fisionomía del paisaje, fisionomía de la naturaliza e fisionomía de combate interrelacionam-se e formam uma rede significativa, mesmo que esta gere alguns paradoxos admitidos pelo narrador.

Ainda no início da viagem, logo em seguida à conversa sobre a relação entre pintura e história, arte e discurso, ao qual nos referimos, Rugendas manifesta sua vontade der ver os índios em ação:

Rugendas volvía a lamentar no haber visto a los indios en acción. Quizás debería haber esperado unos días más... sentía una vaga nostalgia inexplicable de lo que no había pasado, de las enseñanzas que podía haber dejado. ¿Eso quería decir que los indios eran parte del procedimiento? La repetición de los malones era historia concentrada. (p. 31-32)

Durante o malón, as reflexões dos dois se intensificam e ficam cada vez mais relacionadas à parada dos índios.

El procedimiento del combate indios-blancos se reproducía en el de los pintores: había un equilibrio de cercanías y lejanías al que había que sacarle el máximo provecho.... El Tambo fue lo mejor del día, en términos de fisionomía de combate. Lo tomaron desde varios puntos de vista, y durante horas, hasta pasado el mediodía. Fue una constante parada de indios. (p. 73) 
Retoma-se a questão fundamental da representação em relação ao procedimento e agora vista a partir da observação de um malón. Se o procedimento determina a ordem do discurso, os índios fazem parte dessa ordem. Procedimento do combate quer dizer que o combate é a ordem do discurso - na época e hoje. $\mathrm{E}$ sempre repete-se o aspecto da construção a partir dos fragmentos de cenas e episódios:

Las tomas sueltas que había hecho cada uno de ellos no tenían otro objeto que el de formar historias, escenas de historias. Las englobaba la historia general del malón, pero éste era apenas un episodio del largo combate entre las civilizaciones. Desde un nivel de la fragmentación se reconstruía otro nivel. (p. 76)

O motivo do enfrentamento ou combate das civilizações deve ser visto como uma dimensão do encontro com o Outro em geral. O texto sugere essa leitura porque toca no motivo focalizando outras dimensões também. Numa das reflexões durante o malón, a compreensão da atividade psíquica é refletido a partir do procedimento humboldtiano:

Los dos alemanes seguían en la suya. Las nuevas impresiones del Malón reemplazaban a las viejas. A lo largo de la jornada se produjo una evolución, que no se completó, hacia un saber no mediado. Hay que tener en cuenta que el punto de partida era una mediación muy laboriosa. El procedimiento humboldtiano era un sistema de mediaciones: la representación fisionómica se interponía entre el artista y la naturaleza. La percepción directa quedaba descartada por definición. Y sin embargo, era inevitable que la mediación cayera, no tanto por su eliminación como por un exceso que la volvía mundo y permitía aprehender al mundo mismo, desnudo y primigenio, en sus signos. Al fin de cuentas, es algo que pasa en la vida de todos los días. 
Uno se pone a charlar con el prójimo, y trata de saber qué está pensando. Parece imposible llegar a averiguarlo si no es por una larga serie de inferencias. ¿Qué hay más encerrado y mediado que la actividad psíquica? Y aun así, ésta se expresa en el lenguaje, que está en el aire y sólo pide ser oído. Uno se estrella contra las palabras, y sin saberlo ya ha llegado al otro lado, y está en el cuerpo a cuerpo con el pensamiento ajeno. A un pintor le pasa lo mismo, mutatis mutandi, con el mundo visible. Le pasaba al pintor viajero. Lo que decía el mundo era el mundo. Y ahora, como complemento objetivo, el mundo había parido repentinamente a los indios. (p. 81-82)

A passagem é exemplar para a abordagem da questão do procedimento pelo narrador. A busca por uma representação sem mediação para chegar corpo-a-corpo com o pensamento do outro, inclusive dos índios. Desta vez o narrador não admite o paradoxal da ideia. Só concede que se trata de um paroxismo. A fórmula do cuerpo a cuerpo se repete no final da novela em relação aos índios.

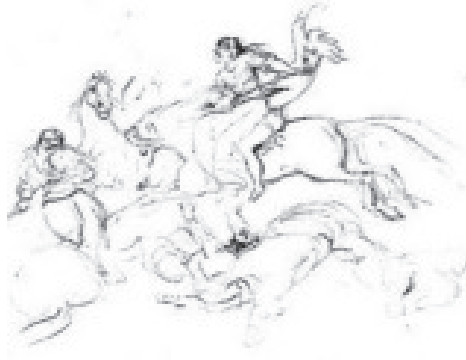

J.M. Rugendas: Batalha campal (esboço)

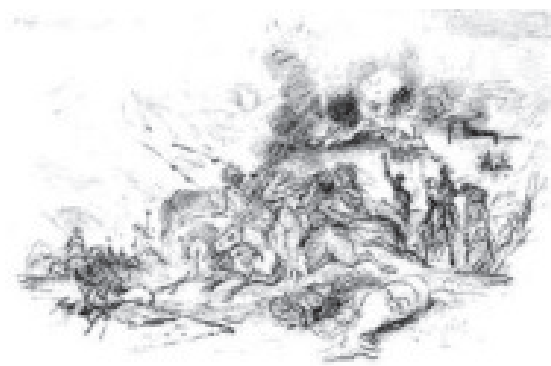

J. M. Rugendas: Orapto $(\text { esboço })^{10}$

\footnotetext{
9 http://www.profesorenlinea.cl/imagenbiografias/rugendas014.jpg

${ }^{10} \mathrm{http}: / / \mathrm{www}$.profesorenlinea.cl/imagenbiografias/rugendas016.jpg
} 


\section{Discurso da cautiva}

Durante o malón há um breve momento de articulação, por uma única vez no texto, de uma voz feminina, quando Rugendas pede uma mantilla para cobrir seu rosto mutilado: "cuando encontraron a la dueña de casa, en la cocina, fue el enfermo el que sacó fuerzas de flaqueza para hacer el insólito pedido de una mantilla de misa calada, negra por convención, eso no necesitaba ni decirse. Las señoras sudamericanas abundaban en esos artículos católicos." (p. 62). A dama parabeniza os visitantes para a tentativa de pintar cenas do malón. Ela se mostra preocupada com a segurança dos dois estrangeiros e diz que eles não precisam se preocupar com ela: "Su escala de valores incluía las incomodidades más escandalosas. Los indios para ellos eran parte de la realidad. ¿El extranjero quería pintarlos? No le veían nada de raro.” (p. 63). Rugendas recebe a mantilla com uma reverência e promete devolvela de noite. "Para esa hora, dijo la señora con una risa heroica, quizás yo ya sea Madame Pehuenche. iDios no lo permita! exclamó Krause inclinándose a besar la mano que ella le tendía." (p. 63).

A articulação desse breve discurso irônico, heróico e submissivo ao mesmo tempo, tem uma função significativa dentro da novela. A senhora refere-se a um ritual dos índios durante um malón: o de capturar mulheres. E Rugendas não vai deixar de observar e desenhar uma cena onde um índio passa no seu cavalo fingindo ter uma mulher raptada nos braços.

Allí venía, dando la vuelta a la colina del torrente, un grupito de salvajes vociferantes, las chuzas en alto: ihuinca! imata! iaaah! iiih! Y en medio de ellos, triunfante, un indio que era el que más gritaba, y traía abrazada, cruzada sobre el cuello del animal, una «cautiva». Que no era tal, por supuesto, sino otro indio, disfrazado de mujer, y haciendo gestos afeminados; pero era tan burdo el engaño que no habría engañado a nadie, ni siquiera a ellos mismos, que parecían tomárselo a la chacota. Y ya fuera por el 
chiste, ya por el valor simbólico del gesto, lo llevaron más lejos. (p. 74)

Sabemos do altíssimo valor simbólico desse gesto na representação pitoresco da América Latina na Europa. Não sabemos se o exotismo e o orientalismo que caracterizaram a visão europeia sobre Espanha na época fez parte da bagagem de Rugendas quando ele atravessou o Atlântico na sua primeira viagem ou se foram influenciados por suas conversas com Domingo F. Sarmiento ou se este projetou suas ideias nos quadros de seu amigo Rugendas. De qualquer forma:

El pintor alemán encontró en Argentina, y más precisamente en una novela argentina, uno de los temas preferidos de la pintura orientalista decimonónica en Europa, o uno de los tópicos del género: el del rapto, e implícita violación, de la mujerblanca-por un salvaje de color cobrizo o moreno, tema que Sarmiento tilda de "poema épico de la pampa". Rugendas hizo esta serie de pinturas para ilustrar La cautiva, poema narrativo costumbrista de otro correligionario de Sarmiento, el igualmente exiliado Echeverría. [6] De hecho, el emperador brasileño le compró una serie de ellas, dato consignado por el mismo Sarmiento (74), quien describe las escenas de rapto de cristianas pintadas por Rugendas con lujo de detalles. Al concluir su descripción agrega que estas imágenes suministran "contrastes en las razas, de trajes em la civilización de la víctima i la barbarie del raptor." 11

Com essa referência lembramos um aspecto da ordem do discurso da época em que o episódio descrito na novela teria acontecido. Analisando as cartas de Sarmiento, Sena argumenta que a orientalização da paisagem e a reflexão sobre o conflito entre

\footnotetext{
${ }^{11}$ SENA. Beduinos en la Pampa: el espejo oriental de Sarmiento, p. 4.
} 
civilização e barbárie se confundiram na representação artística e que Rugendas, na tradição de Humboldt, teria servido de pretexto para introduzir e legitimar a noção do caráter árabe inscrito na paisagem geográfica e humana da Argentina. Para a autora, tratase da construção de uma imagem na tradição da fisionomia de natureza: "Lo que llama la atención, por lo tanto, es precisamente cómo a lo largo de las cartas se va construyendo esta "fisonomía árabe" de España y de Argentina". ${ }^{12}$

\section{A parte final do episódio}

Tendo em vista essa ordem do discurso, a última parte da novela talvez fique menos inexplicável do que o narrador sugere quando afirma: "Esta parte final del episodio fue más inexplicable todavía que el resto. Pero no podemos dudar de su realidad porque quedó documentada en el epistolario posterior del artista." (p. 87). É um jogo do narrador onde as instâncias narrativas se confundem. O próprio narrador aplica a ironia que ele atribui às palavras contidas nas cartas do pintor para sua família. Mesmo assim, podemos pelo menos tentar explicar melhor do que o narrador alguns aspectos dessa parte final, tendo em vista a ordem do discurso do episódio.

Este final da novela é como um finale de uma peça musical. Toca-se mais uma vez nos principais motivos da obra toda. O leitmotiv continua o da representação, em especial a da artística, e o procedimento a serviço de um mercado. Os outros motivos na novela são tocados também: o malón, os índios, a voz feminina, o raio, a verdade e o cuerpo a cuerpo do encontro com o outro.

A representação artística ganha, nessa parte final, mais uma valorização enfática. Aproveitando o fato de que as produções artísticas do pintor chegariam qualquer forma ao seu destino em Augsburg depois da sua morte, o narrador comenta:

${ }^{12}$ SENA. Beduinos en la Pampa: el espejo oriental de Sarmiento, p. 6. 
¿qué podía pasarle? Que lo mataran, nada más. Y eso era un detalle sin importancia. De hecho, cuando sus corresponsales vieran los cuadros resultantes, es decir cuando su producción llegara a las galerías o museos europeos, con toda seguridad él ya habría muerto. El artista, en tanto artista, siempre podía estar muerto. ... Rugendas podía decir como todos, y especialmente después de lo que le había pasado: "ya v"ví bastante". Como el arte es eterno, no se pierde nada. (p. 88)

Na maior parte da novela, a partir do tratamento com ópio e morfina após ser atingido pelos raios da tempestade elétrica, Rugendas é apresentado como trabalhando numa espécie de transe intuitivo, conforme uma visão romântica do artista. Nesse estado e apesar do espanto do seu amigo, ele resolve ir ao encontro dos índios que estavam comemorando o fim do malón com muita comida e bebida e sem as mulheres, que estavam esperando preocupadas em casa:

Decir que quedaron atónitos al ver irrumpir en el círculo de luz al pintor monstruo, sería poco. No daban crédito a sus ojos. No podían. Eran una fraternidad de hombres: no había mujeres ni niños entre ellos. Si hubieran querido, dijeran lo que dijeran, habrían podido volver con el botín a sus tiendas en unas pocas horas de marcha. Pero se tomaban la noche libre: con la excusa del malón, dejaban a sus esposas esperando, preocupadas y muertas de hambre. (p. 88-89)

Neste momento abre-se a enorme distância entre o pintor branco europeu e os nativos:

La borrachera y el sentimiento de culpa se les juntaron en un espanto único al ver ese rostro iluminado por la luna, ese hombre que se había vuelto todo cara. $\mathrm{Ni}$ siquiera vieron lo que hacía: lo veían a él. Jamás 
podrían haber adivinado de dónde salía. ¿Cómo iban a saber que existía un procedimiento de representación fisionómica de la naturaleza, un mercado ávido de grabados exóticos, etcétera? Si ni siquiera sabían que existía el arte de la pintura; y no porque no lo tuvieran, sino porque lo tenían en la forma de un equivalente, cualquiera que fuese (no sabían cuál era). (p. 89)

Rugendas por sua vez começa seu desenhar frenético. Parece que os raios que passaram por seu corpo e cabeça agora se projetam nos rostos dos índios nada bonitos em termos de padrões europeus:

Ahora sí los tenía cerca, con todos los detalles: las bocazas de labios como salchichones aplastados, los ojos de chino, la nariz como un ocho, las crenchas duras de grasa, los cuellos de toro. Los dibujaba en un abrir y cerrar de ojos. Estaba aceleradísimo (en términos de procedimiento) por el efecto de rebote de la morfina. Pasaba de una cara a otra, de una hoja a la siguiente, como el rayo que cae sobre la pradera. (p. 89)

Sem saber, sem voz, as chamas do fogo "dándole movimiento al gesto absorto, y actividad de continuo a la estupefacción idiota" confrontados com o "que más había temido el Malón en sus muchas manifestaciones en el curso del tiempo: el cuerpo a cuerpo" (p. 89), o artista lhes traz sua verdade:

En la noche de una jornada de correría se presentaba un pintor a revelarles la verdad alucinada de lo que había pasado. Empezaron a gemir las lechuzas en los bosques profundos, y los indios aterrorizados quedaban fijados en remolinos de sangre y óptica. A la luz bailarina del fuego, sus rasgos dejaban de pertenecerles. (p. 90) 
O pintor que parece cumprir a missão de por os índios de volta ao centro da fábula e ao mesmo tempo parece estar roubandolhes sua identidade; ele, por sua vez, não é o dono das suas ações. $\mathrm{Na}$ penúltima frase ficamos sabendo: "Drogado por el dibujo y el opio, en la medianoche salvaje, efectuaba la contigüidad como un automatismo más. El procedimiento seguía actuando por él.” (p. 91)

Para entender melhor algumas ambiguidades que marcam a descrição do encontro do pintor com os índios, lembramos a data desta segunda viagem de Rugendas à Argentina. Parece ser uma estratégia discursiva do narrador como ele confunde o leitor no primeiro parágrafo e só na página 14 diz com clareza: "Partió a fines de diciembre de 1837". Já mencionamos a conexão entre Rugendas e Sarmiento, que era uma amizade de longos anos, e chegamos à conclusão de que o discurso da geração de 1837, movimento da qual Sarmiento participou como um dos lideres intelectuais, está presente na novela, principalmente na sua parte final. Shumway comenta a postura ambivalente desse representante da geração de '37:

Like the Romantics he read, Sarmiento is fascinated by the horrific power of electrical storms ... Civilization or Barbarism are the choices Sarmiento offers us, and to a degree those terms became the rallying cry of the entire Generation. Yet the obvious choice Sarmiento dictates of civilization over barbarism masks a complex ambivalence much studied by literary scholars like Noe Jitrik, Beatriz Sarlo, and Carlos Alonso. While Sarmiento, the liberal progressive, wants to eradicate all vestiges of "barbarism," Sarmiento, the romantic poet, finds the gaucho attractive ... He is similarly drawn to the titanic personality of the caudillo, the primitive hero who defies and transcends human law. Although undeniable on a literary level, such ambivalence all but disappeared in Sarmiento's public life, where he consistently sought to eradicate gaucho and Indian life (by extermination if necessary), exclude 
dissenters, and force survivors into his vision of civilization: a modern, Europeanized Argentina. ${ }^{13}$

A ambivalência tanto do protagonista quanto do narrador pode ser explicada em vista da influência de uma figura ambígua como Sarmiento. Podemos supor que o narrador sabia da admiração dele em relação a Rugendas "a quien caracteriza como 'um historiador mas que um paisajista', Sarmiento alaba la fidelidad de sus pinturas, verdadeiros 'documentos'".${ }^{14} \mathrm{O}$ pintor da novela tem seus traços românticos e ao mesmo tempo lança mão de ideias circulando na virada dos séculos $\mathrm{XX} / \mathrm{XXI} .{ }^{15} \mathrm{O}$ narrador é ambivalente no seu posicionamento narrativo, falando de fora ou de dentro do pintor, conhecendo seus nervos e pensamentos, porém às vezes distanciando-se deles. Isso leva à ambiguidade das últimas páginas que descrevem a parte final do episódio que o narrador declara como mais inexplicável do que o resto. Tentamos explicar, mas ficam dúvidas sobre como o leitor deve entender ou interpretar frases como:

En la noche de una jornada de correría se presentaba un pintor a revelarles la verdad alucinada de lo que había pasado. Empezaron a gemir las lechuzas en los bosques profundos, y los indios aterrorizados quedaban fijados en remolinos de sangre y óptica. (p. 90-91)

\section{Conclusão}

Depois da verificação do nosso argumento inicial, podemos concluir que a textura da novela é composta por uma rede de motivos e discursos inter-relacionados. Como o leitmotiv do procedimento refere-se a Alexander von Humboldt como o "segundo descobridor" da América Latina, a relevância da novela

\footnotetext{
${ }^{13}$ SHUMWAY. The invention of Argentina, p. 134.

${ }^{14}$ SENA. Beduinos en la Pampa: el espejo oriental de Sarmiento, p. 4.

${ }^{15}$ FITZ. Wir blicken in ein ersonnenes Seben, p. 12.
} 
para a memória cultural fica evidente. O protagonista Moritz Rugendas, figura parte factual parte ficcional, faz uma viagem nos pampas argentinos em busca da revisão ou reversão do procedimento humboldtiano. Interpretamos essa viagem como uma alegoria da busca da verdade, pois no final do texto lemos "En la noche de una jornada de correría se presentaba un pintor a revelarles la verdad alucinada de lo que había passado", referindo-se ao acontecido, em 1837.

Lembrando a amizade de Rugendas com Sarmiento, um dos exponentes da geração de ' 37 na Argentina, constatamos que a novela se enquadra na ordem do discurso naquele momento tanto em termos de representação artística quanto em termos sócio-políticos do Nuevo Mundo. A novela conta como Humboldt definiu a ordem da representação e que Rugendas buscou desmentir o mestre. Nas reflexões em torno dessa questão, identificamos uma dimensão universal e local. Rugendas chega a se perguntar se os índios fazem parte do procedimento. Algumas das reflexões e conclusões do pintor são bastante paradoxais. Porém, não vamos nos aprofundar nessas questões. Focalizamos, ao contrário, o aspecto da memória cultural e constatamos, como na observação e documentação artística de um malón, como as questões da ordem da representação e do discurso se tornam visíveis e o texto transmite a imagem do artista documentando intuitivamente os movimentos de um combate das civilizações.

As ambiguidades e paradoxos do texto, explicamos como resultado da ordem do discurso da época: de um lado, o protagonista, e de outro, o narrador. Mostramos a proximidade de Rugendas com Sarmiento. O narrador, na virada dos séculos $\mathrm{XX} / \mathrm{XXI}$ enquadra-se em tendências literárias que se orientam por teorias como a do construtivismo radical e do caos, valorizando uma escrita multiperspectivista. A novela é um texto complexo e rico sobre o autor factual de Viaje pintoresco por el Brasil que, em cena ficcional nas redondezas de Mendoza, vai ao encontro dos índios e a eles revela a verdade sobre o que teria acontecido, pintando e construindo história concentrada, ou memória cultural. 
Resumen: Analizamos la novela Un episodio en la vida del pintor viajero, de César Aira, desde el punto de vista de la representación de la memoria cultural latinoamericana. Argumentamos que el viaje narrado en el texto es una alegoría de la búsqueda de un procedimiento artístico que sería mejor que el discurso teórico-científico, en la realidad. Mostramos como el texto sugiere que cada discurso se encuadra en un orden y el procedimiento artístico se encuadra en el orden de la representación. Ese orden fue determinado por la visión europea en la cual se destacaron dos íconos de la memoria latinoamericana, Alexander von Humboldt y Johann Moritz Rugendas, el protagonista de la novela. Desde el punto de vista del nuestro análisis, y también del nuestro argumento, focalizamos aspectos que la crítica y los comentaristas han ignorado, como el de que la cuestión de la representación de la memoria histórica estaría relacionada al encuentro violento del hombre blanco con el indio en un combate de civilizaciones. Aplicamos en este artículo, nuestro modelo de análisis de la interdiscursividad de textos culturales.

Palabras-clave: Memoria cultural; discurso; representación; Alexander von Humboldt; Johann Moritz Rugendas.

\section{Referências}

AIRA, C. Humboldts Schatten. München: Nagel \& Kimche im Carl Hanser Verlag, 2003.

AIRA, C. Un episodio en la vida del pintor viageiro. Rosario: Beatriz Viterbo Ed., 2000.

AUGUSTIN, G. Kultur als Text, Text als Diskurs - Interdiskursive Analyse interkultureller Texte. In: KRAMER, A.; RÖHNERT, J. (Hg.) Literatur Universalie und Kulturspezifikum. Göttingen: Universitätsverlag Göttingen, 2010. p. 25-34.

AUGUSTIN, G. Literatura de viagem na época de João VI. Belo Horizonte: Ed. da UFMG; 2009. 
ETTE, O. Nachwort. In: AIRA, C. Humboldts Schatten. München: Nagel \& Kimche im Carl Hanser Verlag, 2003. p. 99-123.

ETTE, O. Überlebenswissen. Berlin: Kulturverlag Kadmos, 2004.

FERNÁNDEZ, N. Narraciones viajeras: César Aira y Juan José Saer. Buenos Aires: Biblos. 2000.

FITZ, A. Wir blicken in ein ersonnenes Seben. Wirklichkeits- und Selbstkonstruktion in zeitgenössischen Romanen. St Ingbert: Röhrig Universitätsverlag, 1998.

KRAMER, A.; RÖHNERT, J. (Hg.) Literatur - Universalie und Kulturspezifikum. Göttingen: Universitätsverlag Göttingen, 2010.

SENA, I. de. Beduinos en la Pampa: el espejo oriental de Sarmiento. <Disponível em http://magyar-irodalom.elte.hu/palimpszeszt/ 23_szam/04.html; acesso em 20.01.2011>

SHUMWAY, N. The invention of Argentina. Berkeley: The University of California Press, 1992. 